\title{
EFFECT OF THE INFORMATION SUPPORT METHOD COMBINED WITH YOGA EXERCISE ON THE DEPRESSION, ANXIETY, AND SLEEP QUALITY OF MENOPAUSAL WOMEN
}

\author{
Xi Lu' ${ }^{1}$ Lu Liu' ${ }^{2} \&$ Rui Yuan ${ }^{3}$ \\ ${ }^{I}$ Department of Public Physical and Art Education, Zhejiang University, Hanzhou, China \\ ${ }^{2}$ Department of Physical Education and Sport, Shanghai Ocean University, Shanghai, China \\ ${ }^{3}$ College of Arts and Science, Shanghai Maritime University, Shanghai, China
}

received: 26.2.2020;

revised: 15.4.2020;

accepted: 5.5.2020

\begin{abstract}
SUMMARY
Background: Menopause is a special stage in a woman's life, but no safe clinical treatment exists against menopausal symptoms. To analyze the effect of the information support method combined with yoga exercise on the depression, anxiety, and sleep quality of menopausal women.

Subjects and methods: From June 2019 to December 2019, menopausal women who were newly recruited in three yoga clubs in three cities in East China were selected as the participants by convenience sampling. A total of 52 women were in the experiment group and 54 were in the control group. In 24 weeks, the experiment group engaged in yoga exercise for 60 minutes each time, three times a week. They group was given professional positive psychological information support at the same time. The Kupperman Menopausal Symptom Distress Scale, Self-rating Depression Scale (SDS), Self-rating Anxiety Scale (SAS), and Pittsburgh Sleep Quality Index (PSQI) were used before the experiment, three months into the experiment, and six months into the experiment to monitor the intervention effect on the participants.

Results: After the intervention, the symptoms of distress among menopausal women in the experiment group and the Kupperman score of the experiment group reduced significantly. Repeated measures of analysis of variance were conducted in the two groups $(P<0.001)$. After the intervention, the depression score of the experiment group decreased significantly. A significant difference was found between the two groups in repeated measures analysis of variance in the SDS score $(P<0.001)$. After the intervention, the anxiety score of the experiment group reduced significantly, and repeated measures of analysis of variance in the SAS score were conducted in the two groups $(P<0.001)$. After the intervention, the sleep quality of the experiment group improved, and repeated measures of analysis of variance in sleep quality were conducted in the two groups $(P<0.001)$.

Conclusions: The information support method combined with yoga exercise can alleviate the depression and anxiety of menopausal women, improve their sleep quality, and reduce their symptoms of menopausal distress.
\end{abstract}

Key words: information support method - menopausal women - depression - anxiety - sleep quality

\section{INTRODUCTION}

Menopause is a special stage in a woman's life. Menopause refers to a gradual physiological transition period from normal menstruation to menstrual disorders and final menolipsis (Azarbal et al. 2016). The entire period lasts approximately 20 years and is a natural part of a woman's life. Menopause mostly occurs between the ages of 45 and 55, and its first manifestation is a change in menstrual disorders, a stage in which women transition from the reproductive to infertile ages. The major cause of menopause is the gradual decline in hormone levels from the gradual recession in ovarian physiological functions. The symptoms often comprise interactive syndromes such as autonomic neurological disorders and metabolic disorders (Lee et al. 2016). The main manifestations of female menopause include insomnia, dreaminess, dizziness, fever, palpitation, sweating, fatigue, depression, anxiety, fear, nervousness, sensitivity, suspiciousness, and irritability, collectively known as menopausal syndrome (Haas et al. 2016). A woman may not have all the symptoms above. Instead, the degree and duration of the symptoms are determined by the individual's physical condition and environment. Menopause often represents the passing of reproductive age and women's gradual transition from middle age to old age. A series of physical and psychological problems occur during the transition (Zhao et al. 2018). AlMehaisen and Al-kuran (2018) found in a cross-sectional survey on more than 30,000 menopausal women that menopause results in common effects on women's quality of life and that more than $90 \%$ of menopausal women generally report a decline in their quality of life. In addition to certain basic physical menopausal symptoms such as hot flashes, sweating, and headache (Hildreth et al. 2018), certain emotional symptoms, triggered by physical and mental factors together, appear in sequence due to dramatic changes in hormone levels. One of the problems faced by menopausal women is emotional disorders. A meta-analysis on the prevalence of depression among Chinese menopausal women indicated that the prevalence of depression among Chinese menopausal women is as high as $36.3 \%$, and the prevalence of moderate and severe depression is 
as high as $15.3 \%$ and $3.7 \%$ (Zeng et al. 2019). The prevalence of anxiety that often occurs with depression is also not optimistic (Mulhall et al. 2018). Emotional disorders affect the mental health of menopausal women and their sleep quality. Sleep problems have become one of the common physical health problems among menopausal women (Lampio et al. 2017, Rodriguez et al. 2019). Depression, anxiety, and sleep quality problems gradually affect each other, forming either a vicious or a benign cycle. Thus, active external intervention plays an important role in regulating this cycle.

At present, no safe clinical treatment exists against menopausal symptoms. Medically, menopausal symptoms are treated by sedation, hypnosis, hormone alternative therapy, and drugs that relieve depression (Guo \& Liu 2015, Pizzi et al. 2020). Although these common methods have a fast onset and strong effect, certain side effects remain. For instance, these methods are likely to result in drug tolerance and dependency, and long-term use may even damage liver and kidney functions, increasing the risk of cancers (Lin \& Pan 2018). Exercise as a positive intervention has elicited the attention of medical researchers because it is simple, convenient, safe, and effective. The results of several related studies have shown that exercise can effectively relieve people's negative emotions and improve sleep quality. Studies have found that aerobic exercise can relieve psychological stress and improve sleep quality (Ströhle 2018). Research shows that exercise can enhance physical fitness while improving mental status, and exercise is therefore an important factor to improve sleep quality (Ren \& Li 2020). The probability of depression among women who do not regularly participate in exercise is twice that of ordinary people (Mastura et al. 2012). Aerobic exercise of no less than 20 minutes can produce anti-depression effects, especially in patients with mild and severe depression (Zhang et al. 2018). Compared with clinical hormonal and other drug therapies, exercise intervention is cheaper, more convenient, and free of side effects. Cramer et al. (2018) conducted a systematic meta-analysis of studies on yoga and menopause syndrome. The results show that yoga has advantages in reducing menopausal syndrome (including depression, anxiety, and sleep disorders). Although exercise has a mitigating effect on menopausal symptoms, studies have pointed out that the lack of scientific exercise knowledge, such as proper exercise length, exercise intensity, and type of exercise, can also lead to poor intervention effects and even more serious adverse effects such as exercise injuries (Ye et al. 2017). Therefore, providing correct disease information support to and develop targeted exercise plans for menopausal patients are extremely important. Psychological hint is a psychological intervention method that offers positive guidance and allows patients to acquire a positive attitude, thereby reducing or even eliminating their disease symptoms. Information support helps improve patients' awareness of the disease, thereby improving their treatment compliance (Li et al. 2018). The positive information support method and the intervention method of yoga exercise have been proven effective in reducing depression and anxiety in menopausal women and improving their sleep quality (Liu \& $\mathrm{Xu}$ 2019). However, no comprehensive study has been conducted on the unique advantages of combining the information support method with yoga exercise. Information support based on positive psychological hints was combined with yoga exercise in this study to intervene in menopausal patients and explore an intervention program that can effectively alleviate the symptoms of menopause, ease depression emotions, and improve sleep quality.

\section{SUBJECTS AND METHODS}

\section{Participants}

From June to December 2019, menopausal women (sometimes referred to here as "patients") who were newly recruited in three yoga clubs in Wenzhou, Hangzhou, and Shanghai in China were selected as the participants by convenience sampling. A total of 52 effective samples are in the experiment group, aged between 45 and 55 years old. The patients have suffered irregular menstruation or natural amenorrhea for more than 12 months. They participated in a 60-minute yoga exercise three times a week for 24 weeks while receiving positive psychological information support. At the same time, menopausal women aged 45-55 years old with irregular menstruation or with natural amenorrhea for more than 12 months (54 effective samples) were randomly selected from communities in Wenzhou. Except for basic housework and normal work, they did not participate in other exercise activities. Inclusion criteria are as follows: 1) those who met the diagnostic criteria for menopause, 2) those who had normal communication skills, and 3) those who participated in the study voluntarily. Exclusion criteria are as follows 1) those with severe liver and kidney diseases or malignant tumors, 2) those with hearing impairments that affect communication, 3) those with mental abnormalities, and 4) out-of-town patients for whom followup is difficult. The samples were randomly divided into 52 patients in the experiment group and 54 in the control group. No statistically significant difference was observed in the general situation data between the two groups, suggesting that the two groups are comparable (Table 1).

\section{Methodology}

Before the intervention, the significance, main methods, intervention time, and precautions of this study were explained to the participants to obtain their cooperation. The participants joined this study voluntarily, and consent was obtained from the guardians of the participants and the community administrators. 
Table 1. Comparison of the basic conditions of the two groups before the intervention $(X \pm S)$

\begin{tabular}{|c|c|c|c|c|}
\hline Factor & Experiment group $(\mathrm{n}=52)$ & Control group $(\mathrm{n}=54)$ & $t / \chi^{2}$ & $\mathrm{P}$ \\
\hline Age & $50.56 \pm 3.27$ & $50.74 \pm 2.95$ & -0.303 & 0.763 \\
\hline Education level & & & 3.582 & 0.167 \\
\hline Junior high school and below & $6(11.54 \%)$ & $14(25.93 \%)$ & & \\
\hline High school/ polytechnic school & $38(73.08 \%)$ & $33(61.11 \%)$ & & \\
\hline College and above & $8(15.38 \%)$ & $7(12.96 \%)$ & & \\
\hline Marital status & & & - & 0.980 \\
\hline Unmarried & $2(3.85 \%)$ & $2(3.7 \%)$ & & \\
\hline Married & $37(71.15 \%)$ & $37(68.52 \%)$ & & \\
\hline Divorced & $8(15.38 \%)$ & $10(18.52 \%)$ & & \\
\hline Widowed & $5(9.62 \%)$ & $5(9.26 \%)$ & & \\
\hline Income & & & 0.757 & 0.860 \\
\hline Below 1000 & $9(17.31 \%)$ & $7(12.96 \%)$ & & \\
\hline $1000-2000$ & $15(28.85 \%)$ & $14(25.93 \%)$ & & \\
\hline $2000-3000$ & $22(42.31 \%)$ & $27(50 \%)$ & & \\
\hline 3000 and above & $6(11.54 \%)$ & $6(11.11 \%)$ & & \\
\hline Menstrual condition & & & 0.116 & 0.734 \\
\hline Menstrual disorders & $35(67.31 \%)$ & $38(70.37 \%)$ & & \\
\hline Natural amenorrhea $<12$ months & $17(32.69 \%)$ & $16(29.63 \%)$ & & \\
\hline Work pattern & & & 3.957 & 0.266 \\
\hline Sitting for a long time & $13(25 \%)$ & $21(38.89 \%)$ & & \\
\hline Standing for a long time & $12(23.08 \%)$ & $12(22.22 \%)$ & & \\
\hline Fieldwork & $5(9.62 \%)$ & $7(12.96 \%)$ & & \\
\hline Housework & $22(42.31 \%)$ & $14(25.93 \%)$ & & \\
\hline Personal medical history & & & 0.129 & 0.719 \\
\hline Yes & $11(21.15 \%)$ & $13(24.07 \%)$ & & \\
\hline No & $41(78.85 \%)$ & $41(75.93 \%)$ & & \\
\hline
\end{tabular}

All the scales in this study were filled in anonymously. Afterward, each participant was given a small gift, such as a scarf. Conventional medical interventions such as health education, psychological care, diet guidance, medication guidance, and discharge guidance were given to the two groups at the same time. Based on conventional treatment, yoga exercise and positive information support counseling were provided to the experiment group. The specific measures include (1) positive psychological hints, as follows. A) Language hints: different dialogues were designed according to the patients' different personalities and characteristics. Hints were consciously given to the patients by dialogue during yoga exercise to indicate that the symptoms of menopause can be effectively relieved. B) Behavior hints: in addition to correcting the patients' negative cognition of menopausal treatment promptly, necessary and correct health behavior hints were also provided. C) Model hints: the yoga exercise teams were arranged reasonably. When conditions permitted, those patients with depression and other symptoms were included in the same exercise team as those with cheerful personalities, so that they could be positively affected subtly. (2) Information support is as follows. A) Evaluation: the investigator spoke with the patient to obtain a preliminary understanding of the patient's personalities, characteristics, educational level, living environment, hobbies, lifestyle habits, family lifestyle, and other basic information to evaluate the patient's knowledge of menopause. B) Multi-channel and multi-form health education: gynecologists from community hospitals were invited to incorporate their knowledge of menopausal syndrome, including the causes, clinical manifestations, treatment options, drug effects, and influence of emotions and sleep on the disease, into health prescriptions and health education manuals with rich pictures and texts. The gynecologists also provided regular health knowledge lectures and led the patients to understand that pre-menopausal symptoms are normal physiological changes and that they can easily experience menopause as long as they develop positive healthy life behaviors. The situation of each patient was evaluated to determine what should be understood, and one-to-one key explanation was provided to assist the patient to analyze and correct bad health habits and to improve positive psychotherapy for the patient. C) Peer support: during group lectures, yoga practice, and other crowd-gathering times, peers were encouraged to learn from each other and share exercises and relaxation methods suitable for recovery from the disease, including yoga meditation exercises, relaxation training methods, and acupressure before bed. Participants were encouraged to share happy things with others to ease the mood, relax the mind, and promote sleep. D) Continuous information support: WeChat groups were established to regularly release relevant disease knowledge; 
follow up on the patients' diet, activities, emotions, sleep, and other conditions; and answer their questions promptly. Those with privacy protection needs were contacted via WeChat individually, and telephone follow-up was conducted once every two weeks for those who could not access the Internet. During WeChat, telephone follow-up, or follow-up visits, positive psychological information support was continued to provide the patients with positive hints and supervision. E) Yoga exercise: yoga exercise was carried out for up to 24 weeks, three times a week, 60 minutes every time. An appropriate combination of yoga exercise was compiled according to the physiological condition of the patient. A professionally trained yoga instructor from the yoga club demonstrated the movements during the intervention, and the instructor used gentle language and movements to guide the patient's training and meditation. Precautions for warming up and exercise were given to the patient before each treatment. After the training was completed, the instructor exchanged experiences, especially the positive and peaceful life attitudes advocated by yoga, with the patient. At the same time, before the intervention, the investigator explained the significance of the study to the participants in the control group and emphasized that they could not participate in any other exercises such as jogging and tai chi for six months.

\section{Measuring Tools}

\section{General Situation Questionnaire}

The questionnaire includes factors such as age, marital status, education level, work pattern, menstruation status, and personal medical history.

\section{Kupperman Menopausal Symptom Distress Scale}

This special scale for scoring menopausal symptoms is the most widely used internationally and domestically. This scale comprises a total of 13 physical and psychological symptoms, and each symptom is assigned a specific index that multiplies the severity of the symptom to calculate the score. The total score is the sum of the scores in the 13 items, and it evaluates the severity of menopausal symptoms. A high score indicates that menopausal symptoms are highly obvious (Liang et al. 2010).

\section{Self-rating Depression Scale (SDS)}

SDS was compiled by Zung and used to evaluate the state and severity of depression in the participants. This scale is filled in according to the participant's personal feelings within one week to intuitively reflect the subjective feelings of the object. SDS includes 20 items in four dimensions of psychological disorders, namely, psychotic emotional symptoms, somatic disorders, psychomotor disorders, and depression. The scale is easy to operate and master, suitable for normal people and mental patients in all types of occupations, cultures, and age groups. A lower total score means a better situation in terms of depression and vice versa (Zung 1965).

\section{Self-rating Anxiety Scale (SAS)}

SAS was compiled by Zung and contains 20 test items that are scored at four levels. SAS mainly evaluates the anxiety of the tested participant at the time or in the last week. The scale can effectively reflect the subjective feelings of the participants for one week. SAS is suitable for people in all occupations, cultures, and ages. SAS is also suitable for adults with anxiety symptoms. Thus, SAS has a wide range of applications (Zung 1971).

\section{Pittsburgh Sleep Quality Index (PSQI)}

This self-rating sleep quality scale compiled by Buysse et al. is one of the most widely used sleep quality assessment scales. It was translated into Chinese by Liu, tested for reliability and validity, and proven suitable for application in China. PSQI is used to evaluate the sleep quality of the tested participants in the last month. PSQI is suitable for people with sleep disorders and for evaluating the sleep quality of ordinary people (Buysse et al. 1989).

\section{Statistical Analysis}

The participants in the two groups were observed before the experiment, three months into the experiment, and six months into the experiment. Dynamic changes in Kupperman Menopausal Symptom Distress Scale, SDS, SAS, and PSQI were used to monitor the effect on the participants. SPSS 18.0 was used for statistical processing and analysis of the data. Descriptive analysis, $\chi^{2}$ test, t-test, and repeated measures analysis of variance were combined for analysis.

\section{RESULTS}

\section{Comparison of the basic conditions between the two groups before the intervention}

The results show no significant difference in the indicators between the two groups, indicating that the two groups are comparable before the intervention.

\section{Repeated measures analysis of variance in SDS scores of the two groups before and after the intervention}

The SDS scores of the participants in the experiment group changed with time, indicating that the difference in the data at each time point is statistically significant. The time and method of SDS score re-intervention show an interactive effect, indicating that the information support method combined with yoga exercise in this study can alleviate the depression of menopausal women. A statistically significant difference was found between the experiment and control groups. Details are shown in Table 2. 
Table 2. Repeated measures analysis of variance in SDS scores of the two groups before and after the intervention

\begin{tabular}{lcccccc}
\hline \multirow{2}{*}{ Group } & $\begin{array}{c}\text { Before } \\
\text { intervention }\end{array}$ & \multicolumn{2}{c}{ After intervention } & At the end & At the end & Time \\
ef 3 months & of 6 months & & Cross-group & Interactive \\
effect & effect \\
\hline Experiment group & $36.62 \pm 2.37$ & $33.12 \pm 2.38$ & $30.22 \pm 2.11$ & $\mathrm{~F}=25.42$ & $\mathrm{~F}=37.21$ & $\mathrm{~F}=27.38$ \\
Control group & $37.04 \pm 2.44$ & $36.69 \pm 2.33$ & $36.33 \pm 2.54$ & $\mathrm{P}<0.001$ & $\mathrm{P}<0.001$ & $\mathrm{P}<0.001$ \\
\hline
\end{tabular}

Table 3. Repeated measures analysis of variance in SAS scores of the two groups before and after the intervention

\begin{tabular}{lcccccc}
\hline \multirow{2}{*}{ Group } & $\begin{array}{c}\text { Before } \\
\text { intervention }\end{array}$ & \multicolumn{2}{c}{ After intervention } & At the end & At the end & Time \\
ef 3 months & of 6 months & & Cross-group & Interactive \\
effect & effect \\
\hline Experiment group & $38.75 \pm 3.3$ & $33.05 \pm 2.76$ & $28.33 \pm 2.71$ & $\mathrm{~F}=287.32$ & $\mathrm{~F}=237.13$ & $\mathrm{~F}=51.23$ \\
Control group & $39.00 \pm 2.8$ & $38.19 \pm 2.79$ & $38.01 \pm 2.14$ & $\mathrm{P}<0.001$ & $\mathrm{P}<0.001$ & $\mathrm{P}<0.001$ \\
\hline
\end{tabular}

\section{Repeated measures analysis of variance in SAS scores of the two groups before and after the intervention}

The SAS scores of the participants in the experiment group changed with time, indicating that the difference in the data at each time point is statistically significant. The time and method of SAS score re-intervention show an interactive effect, indicating that yoga exercise can alleviate the anxiety of menopausal women. A statistically significant difference was found between the experiment and the control groups. Details are shown in Table 3.

\section{Repeated measures analysis of variance in Kupperman symptom scores of the two groups before and after the intervention}

No difference was found between the two groups in Kupperman symptom score before the intervention. However, a significant difference between the two groups was found after the intervention. No difference in the control group was found before and after the intervention, and a significant difference was found in the experiment group before and after the intervention, indicating a significant intervention effect. Details are shown in Table 4.

\section{Effect of the information support method combined with yoga exercise on sleep quality}

The PSQI scores of the experiment group in time to fall asleep, use of hypnotic drugs, and daytime functions changed with time, as did the total score. Apart from sleep disorders and hypnotic drugs, the scores in other PSQI components and the total score show an interacting effect between time and grouping, indicating that the information support method combined with yoga exercise can improve the sleep quality of menopausal women. The comparison between the two groups in the total PSQI score shows a statistically significant difference between the experiment and the control groups. Details are shown in Table 5.

\section{DISCUSSION}

No significant difference is found between the experiment group and the control group in menopausal symptoms before the intervention. However, three and six months into the intervention, menopausal symptoms of women in the experiment group who underwent the information support method combined with yoga exercise reduced significantly, at a level lower than the control group. This finding is consistent with that obtained by Koch et al. (2017), in which menopausal women with breast cancer were the participants. Using randomized experiment group intervention, Koch et al. (2017) also found that yoga exercise can significantly reduce the symptoms of menopausal distress. The following reasons may explain why the information support method combined with yoga exercise can effectively reduce the symptoms of menopausal distress. Many symptoms of menopausal distress, such as sensory abnormality, bone and joint muscle pain, headache, and palpitations, have certain physiological causes. Yoga is a type of physical exercise that can improve physiological functions. For example, yoga exercise can relieve cardiovascular diseases (Loganathan et al. 2019), autonomic nervous system problems (Wang et al. 2019), bone joint and muscle pain (Field 2016), and urinary system diseases (Sha et al. 2019). Yoga can improve the overall physiological health of menopausal women, effectively alleviating their symptoms of distress.

No significant difference was found between the two groups in the depression level before the intervention, both at a relatively high level. However, after three and six months of the intervention, the information support method combined with yoga exercise effectively reduced the depression level of the experiment group. This finding is consistent with that obtained by Levine et al. (2016), who conducted a 12-week yoga intervention in women with depression. They found that yoga exercise can significantly reduce the symptoms of women with depression. The possible reasons for the information support method combined with yoga exercise reducing the depression level of menopausal women are as follows. First, with the information support method, 
Table 4. Repeated measures analysis of variance in Kupperman symptom scores of the two groups before and after the intervention $(\mathrm{X} \pm \mathrm{S})$

\begin{tabular}{|c|c|c|c|c|c|c|c|}
\hline \multirow[b]{2}{*}{ K1 Item } & \multirow[b]{2}{*}{ Group } & \multirow[b]{2}{*}{$\begin{array}{c}\text { Before } \\
\text { intervention }\end{array}$} & \multicolumn{2}{|c|}{ After intervention } & \multirow[b]{2}{*}{$\begin{array}{l}\text { Time } \\
\text { effect }\end{array}$} & \multirow[b]{2}{*}{$\begin{array}{c}\text { Cross-group } \\
\text { effect }\end{array}$} & \multirow{2}{*}{$\begin{array}{c}\text { Interactive } \\
\text { effect }\end{array}$} \\
\hline & & & $\begin{array}{l}\text { At the end } \\
\text { of } 3 \text { months }\end{array}$ & $\begin{array}{l}\text { At the end } \\
\text { of } 6 \text { months }\end{array}$ & & & \\
\hline \multirow[t]{2}{*}{ Hot flashes } & & & $3.62 \pm$ & $1.85 \pm 2.01$ & & & 986 \\
\hline & Control group & & $3.85 \pm$ & & $\mathrm{P}<0.001$ & $\mathrm{P}<0.001$ & $\mathrm{P}<0.001$ \\
\hline \multirow{2}{*}{$\begin{array}{l}\text { Sensory } \\
\text { abnormality }\end{array}$} & Experiment gro & $1.42 \pm 1.07$ & $1.27 \pm 0.97$ & 0.77 & $\mathrm{~F}=4.035$ & $\mathrm{~F}=5.834$ & $\mathrm{~F}=2.435$ \\
\hline & Control group & $1.52 \pm 1.02$ & $1.41 \pm 1$ & $1.41 \pm 1.07$ & $\mathrm{P}=0.019$ & $\mathrm{P}=0.017$ & $\mathrm{P}=0.090$ \\
\hline \multirow[t]{2}{*}{ Insomnia } & Experiment gro & $2.15 \pm 0.54$ & $1.35 \pm 0.95$ & & $\mathrm{~F}=18.950$ & $F=43.765$ & $\mathrm{~F}=18.570$ \\
\hline & Cont & & & & & & \\
\hline \multirow[t]{2}{*}{ Agitation } & Experiment gro & & $1.50 \pm 0.87$ & $1.31 \pm 0.96$ & $\mathrm{~F}=1.742$ & $\mathrm{~F}=0.708$ & .309 \\
\hline & Control group & 1.6 & $1.56 \pm 1.08$ & .02 & $\mathrm{P}=0.178$ & $\mathrm{P}=0.402$ & $\mathrm{P}=0.734$ \\
\hline \multirow[t]{2}{*}{ Depression doubt } & Experiment gro & & $0.04 \pm 0.19$ & & $\mathrm{~F}=7.308$ & $\mathrm{~F}=18.529$ & $\mathrm{~F}=2.128$ \\
\hline & Contr & 0.3 & $0.33 \pm 0.48$ & $0.28 \pm 0.45$ & $\mathrm{P}=0.001$ & $\mathrm{P}<1$ & $\mathrm{P}=0.122$ \\
\hline \multirow[t]{2}{*}{ Dizziness } & Expe & 47 & $0.58 \pm 0.5$ & $0.44 \pm 0.5$ & $\mathrm{~F}=6.190$ & $\mathrm{~F}=9.305$ & $\mathrm{~F}=2.795$ \\
\hline & Control group & & $0.78 \pm 0.46$ & $0.76 \pm 0.55$ & $\mathrm{P}=0.002$ & $\mathrm{P}=0.003$ & \\
\hline \multirow[t]{2}{*}{ Fatigue } & Experiment gro & $1.04 \pm 0.48$ & $0.81 \pm 0.4$ & $0.52 \pm 0.5$ & $\mathrm{~F}=8.234$ & $F=20.578$ & $F=13.056$ \\
\hline & Contro & & $0.93 \pm 0.38$ & $1.04 \pm$ & $\mathrm{P}<0.001$ & $\mathrm{P}<0.001$ & $\mathrm{P}<0.001$ \\
\hline \multirow{2}{*}{$\begin{array}{l}\text { Bone and joint } \\
\text { muscle pain }\end{array}$} & Experim & & $0.62 \pm 0.49$ & & $\mathrm{~F}=12.895$ & $\mathrm{~F}=44.497$ & $F=13.714$ \\
\hline & Control gr & $1.19 \pm 0.55$ & $1.15 \pm 0.63$ & $1.22 \pm 0.46$ & $\mathrm{P}<0.001$ & $\mathrm{P}<0.001$ & $\mathrm{P}<0.001$ \\
\hline \multirow[t]{2}{*}{ Headache } & Experiment gro & $0.83 \pm 0.38$ & $0.58 \pm 0.5$ & $0.38 \pm 0.49$ & $\mathrm{~F}=5.152$ & $F=14.746$ & $\mathrm{~F}=8.574$ \\
\hline & Control group & & $0.8 \pm 0.41$ & $0.81 \pm 0.39$ & $\mathrm{P}=0.007$ & $\mathrm{P}<0.001$ & $\mathrm{P}<0.001$ \\
\hline \multirow[t]{2}{*}{ Palpitation } & Experiment gro & $0.58 \pm 0.57$ & $0.42 \pm 0.5$ & $0.33 \pm 0.47$ & $\mathrm{~F}=3.251$ & $\mathrm{~F}=0.334$ & $\mathrm{~F}=5.629$ \\
\hline & Control group & $0.65 \pm 0.59$ & $0.57 \pm 0.54$ & $0.52 \pm 0.54$ & $\mathrm{P}=0.041$ & $\mathrm{P}=0.717$ & $\mathrm{P}=0.020$ \\
\hline \multirow[t]{2}{*}{ Skin formication } & Experiment group & $0.73 \pm 0.45$ & $0.69 \pm 0.47$ & $0.6 \pm 0.5$ & $\mathrm{~F}=1.368$ & $\mathrm{~F}=2.307$ & $\mathrm{~F}=0.211$ \\
\hline & Control group & $0.78 \pm 0.42$ & $0.78 \pm 0.5$ & $0.72 \pm 0.45$ & $\mathrm{P}=0.257$ & $\mathrm{P}=0.132$ & $\mathrm{P}=0.810$ \\
\hline \multirow[t]{2}{*}{ Sexual life } & Experiment gro & $1.12 \pm 1$ & $0.69 \pm 0.96$ & $0.42 \pm 0.82$ & $\mathrm{~F}=3.997$ & $\mathrm{~F}=10.730$ & $\mathrm{~F}=2.709$ \\
\hline & Control & & $1.11 \pm 1$ & $1.04 \pm 1.01$ & $\mathrm{P}=0.020$ & $\mathrm{P}=0.001$ & $\mathrm{P}=0.069$ \\
\hline \multirow{2}{*}{$\begin{array}{l}\text { Urinary system } \\
\text { infection }\end{array}$} & Experiment grou & $1 \pm 1.01$ & $1.08 \pm 1.01$ & $1.04 \pm 1.01$ & $\mathrm{~F}=0.887$ & $\mathrm{~F}=0.751$ & $\mathrm{~F}=0.961$ \\
\hline & Control group & $0.96 \pm 1.01$ & $1 \pm 1.01$ & $1.04 \pm 1.01$ & $\mathrm{P}=0.120$ & $\mathrm{P}=0.102$ & $\mathrm{P}=0.040$ \\
\hline \multirow[t]{2}{*}{ Total K1 score } & Experimes & $16.69 \pm 2.74$ & $13.23 \pm 2.61$ & $9.08 \pm 3.26$ & $\mathrm{~F}=63.480$ & $\mathrm{~F}=104.972$ & $\mathrm{~F}=52.309$ \\
\hline & Control group & $16.61 \pm 2.23$ & $16.41 \pm 2.83$ & $16.24 \pm 2.57$ & $\mathrm{P}<0.001$ & $\mathrm{P}<0.001$ & $\mathrm{P}<0.001$ \\
\hline
\end{tabular}

Table 5. Repeated measures analysis of variance in sleep therapy of the two groups before and after the intervention $\underline{(\mathrm{X} \pm \mathrm{S})}$

\begin{tabular}{llcccccc}
\hline \multirow{2}{*}{ Item } & Group & $\begin{array}{c}\text { Before } \\
\text { intervention }\end{array}$ & $\begin{array}{c}\text { After intervention } \\
\text { At the end }\end{array}$ & $\begin{array}{c}\text { At the end } \\
\text { of months }\end{array}$ & $\begin{array}{c}\text { Time } \\
\text { effect }\end{array}$ & $\begin{array}{c}\text { Cross-group } \\
\text { effect }\end{array}$ & $\begin{array}{c}\text { Interactive } \\
\text { effect }\end{array}$ \\
\hline Sleep therapy & Experiment group & $1.33 \pm 0.76$ & $1.23 \pm 0.67$ & $1.01 \pm 0.71$ & $\mathrm{~F}=2.815$ & $\mathrm{~F}=3.56$ & $\mathrm{~F}=0.891$ \\
& Control group & $1.37 \pm 0.78$ & $1.34 \pm 0.72$ & $1.35 \pm 0.78$ & $\mathrm{P}=0.061$ & $\mathrm{P}=0.037$ & $\mathrm{P}=0.378$ \\
Time to fall & Experiment group & $1.58 \pm 0.64$ & $1.42 \pm 0.61$ & $1.30 \pm 0.59$ & $\mathrm{~F}=5.091$ & $\mathrm{~F}=4.39$ & $\mathrm{~F}=0.312$ \\
asleep & Control group & $1.48 \pm 0.64$ & $1.45 \pm 0.72$ & $1.49 \pm 0.70$ & $\mathrm{P}=0.009$ & $\mathrm{P}=0.012$ & $\mathrm{P}=0.723$ \\
Length & Experiment group & $0.98 \pm 0.67$ & $0.88 \pm 0.61$ & $0.59 \pm 0.64$ & $\mathrm{~F}=2.342$ & $\mathrm{~F}=5.81$ & $\mathrm{~F}=0.895$ \\
of sleep time & Control group & $0.91 \pm 0.59$ & $0.96 \pm 0.55$ & $0.99 \pm 0.57$ & $\mathrm{P}=0.103$ & $\mathrm{P}=0.003$ & $\mathrm{P}=0.372$ \\
& Experiment group & $0.58 \pm 0.5$ & $0.54 \pm 0.48$ & $0.53 \pm 0.51$ & $\mathrm{~F}=0.313$ & $\mathrm{~F}=0.001$ & $\mathrm{~F}=0.151$ \\
Sleep efficiency & Control group & $0.63 \pm 0.49$ & $0.63 \pm 0.44$ & $0.63 \pm 0.45$ & $\mathrm{P}=0.781$ & $\mathrm{P}=0.999$ & $\mathrm{P}=0.798$ \\
Sleep disorders & Experiment group & $1.23 \pm 0.67$ & $1.09 \pm 0.61$ & $1.00 \pm 0.63$ & $\mathrm{~F}=1.222$ & $\mathrm{~F}=3.49$ & $\mathrm{~F}=0.781$ \\
& Control group & $1.19 \pm 0.65$ & $1.20 \pm 0.63$ & $1.18 \pm 0.63$ & $\mathrm{P}=0.389$ & $\mathrm{P}=0.049$ & $\mathrm{P}=0.371$ \\
Hypnotic drugs & Experiment group & $0.27 \pm 0.45$ & $0.19 \pm 0.44$ & $0.10 \pm 0.48$ & $\mathrm{~F}=5.821$ & $\mathrm{~F}=1.02$ & $\mathrm{~F}=1.114$ \\
& Control group & $0.33 \pm 0.48$ & $0.28 \pm 0.43$ & $0.23 \pm 0.49$ & $\mathrm{P}=0.002$ & $\mathrm{P}=0.920$ & $\mathrm{P}=0.347$ \\
Daytime & Experiment group & $1.67 \pm 0.58$ & $1.31 \pm 0.51$ & $1.30 \pm 0.57$ & $\mathrm{~F}=7.881$ & $\mathrm{~F}=4.81$ & $\mathrm{~F}=1.892$ \\
functions & Control group & $1.61 \pm 0.6$ & $1.55 \pm 0.61$ & $1.60 \pm 0.62$ & $\mathrm{P}<0.001$ & $\mathrm{P}=0.015$ & $\mathrm{P}=0.210$ \\
Total & Experiment group & $7.63 \pm 1.52$ & $6.57 \pm 1.23$ & $6.01 \pm 1.44$ & $\mathrm{~F}=18.340$ & $\mathrm{~F}=16.11$ & $\mathrm{~F}=7.911$ \\
PSQI score & Control group & $7.52 \pm 1.41$ & $7.50 \pm 1.42$ & $7.47 \pm 1.37$ & $\mathrm{P}=0.000$ & $\mathrm{P}=0.000$ & $\mathrm{P}=0.005$ \\
\hline
\end{tabular}


menopausal women have a more correct and comprehensive understanding of menopause, realizing that menopause is a normal and necessary stage in the life, that various changes in physiology and psychology are also normal reactions, and that evasion accelerates aging instead of assisting them to successfully undergo this period (Levine et al. 2016). Correct cognition improves menopausal women's sense of control over menopause, whereas the lack of control is a key factor leading to individual depression (Georgakis et al. 2016). Hence, improving self-control also reduces the depression level. Second, yoga exercise has the characteristic of mindfulness, emphasizing that individuals should focus on important things in the moment (Yang et al. 2018). Therefore, yoga decreases the attention to negative emotions and negative events, improving the level of depression on a cognitive, emotional, and even physical basis (Broughton 2016).

No significant difference was found between the two groups in anxiety level before the intervention. Both were at a relatively high level. However, after three and six months of the intervention, the information support method combined with yoga exercise effectively reduced the anxiety level of the menopausal women in the experiment group. This finding is consistent with those of the meta-analyses by Cramer et al. (2018) and Hofmann et al. (2016). Depression and anxiety are often symbiotic emotional disorders, and their causes share many similarities (Kroenke et al. 2019). Apart from the aforementioned reasons why the information support method combined with yoga exercise can effectively reduce depression, certain psychosocial reasons can also be used to explain the decline in the anxiety level. First, the information support method helps menopausal women improve their self-efficacy, thereby reducing their anxiety. Ebrahimi \& Rahimi (2019) used a randomized experiment group and a control group to examine the effect of improved self-efficacy on menopausal symptoms (including anxiety). They found that the improvement in menopausal women's self-efficacy brought by the information support method can effectively relieve their anxiety symptoms. Second, in addition to the nature of mindfulness, yoga exercise also plays the other very important role of providing social support. Social support is an important psychological resource for individuals to effectively reduce depression and anxiety, especially when individuals particularly need this type of social support (Vodermaier \& Linden 2019). Menopausal women are faced with not only a decline in physical functions but also a decline in confidence of self-ability. Considering this strong sense of difference, menopausal women urgently need social support to supplement their psychological resources and relieve their anxiety (Erbil \& Gümüşay 2018).

Before the intervention, no significant difference was found between the experiment group and the control group in sleep quality score. However, as the inter- vention progressed, the sleep quality of the experiment group improved significantly compared with the level before the intervention and the level of the control group. The information support method combined with yoga exercise can effectively improve the sleep quality of menopausal women for two reasons. First, the information support method combined with yoga exercise effectively improves the physiological functions of menopausal women. For example, yoga exercise can balance the excitement suppression process of the sympathetic nervous system, reducing nervous tension and enhancing the system's ability to regulate, relieve fatigue, speed up sleep, and promote deep sleep (Rao et al. 2017). Yoga exercise can also promote the secretion of endorphins and has the function of hypnosis (Halpern et al. 2014), thereby effectively improving the sleep quality of menopausal women. Second, the improvement in the depression and anxiety of menopausal women brought by the information support method combined with yoga exercise in turn positively affects their sleep quality. Within the same functional organization, the body and the mind are interconnected and influence each other. The improvement in psychological functions contributes to the improvement in physiological functions. Similarly, when the psychological pressure faced by menopausal women is reduced and the level of depression and anxiety is reduced, their sleep quality would improve accordingly (Li \& Lu 2017).

\section{CONCLUSION}

The positive information support method combined with yoga exercise was used in this study to intervene in the experiment group, while no intervention was conducted in the control group. Symptoms of distress, depression, anxiety, and sleep quality of the two groups were examined before the intervention, after three months of the intervention, and after six months of the intervention. The following results were obtained by analysis. First, the six-month information support method combined with yoga exercise was proven to effectively improve the overall symptoms of menopausal distress in the experiment group. Second, the six-month information support method combined with yoga exercise can effectively improve the depression and anxiety of menopausal women and promote their sleep quality. However, despite the acquisition of certain meaningful results, no in-depth investigation was conducted to examine the relationship between the symptoms of distress, depression, anxiety, and sleep quality during menopause. Whether the symptoms of distress, depression, anxiety, and sleep quality of menopausal women at three months of intervention have a predictive effect on the symptoms at six months of intervention will be further investigated by our team. 
Acknowledgements: None.

\section{Conflict of interest: None to declare.}

\section{Contribution of individual authors:}

Conceptualization, investigation: Xi Lu \& Lu Liu;

Methodology, writing - review and editing: Xi Lu \& Rui Yuan;

Formal analysis, data, writing - original draft preparation: Xi Lu;

All authors have read and agreed to the published version of the manuscript.

\section{References}

1. Al-Mehaisen L, Al-kuran O: Impact of menopause on quality of life: A cross sectional study in menopausal females in the north of Jordan. Medical Science and Discovery 2018; 5:234-238

2. Azarbal F, Stefanick ML, Assimes TL, Manson JE, Bea $J W, L i W$, et al: Lean body mass and risk of incident atrial fibrillation in post-menopausal women. European heart journal 2016; 37:1606-1613

3. Broughton MK: Yoga for depression and anxiety: $A$ review of published research and implications for healthcare providers. Rhode Island Medical Journal 2016; 99:20

4. Buysse DJ, Reynolds CF, Monk TH, Berman SR, Kupfer DJ: The Pittsburgh Sleep Quality Index: a new instrument for psychiatric practice and research. Psychiatry Research 1989; 282:193-213

5. Cramer H, Peng W, Lauche R: Yoga for menopausal symptoms - A systematic review and meta-analysis. Maturitas 2018; 109:13-25

6. Ebrahimi $M \&$ Rahimi B: The effect of self-efficacy counseling on the management of menopausal symptoms in psychological dimension in perimenopause women referred to health centers in Mahabad city. Menopause 2019; $3: 5$

7. Erbil $N$ \& Gümüşay M: Relationship Between Perceived Social Support and Attitudes Towards Menopause among Women and Affecting Factors. Middle Black Sea Journal of Health Science 2018; 4:7-18

8. Field T: Knee osteoarthritis pain in the elderly can be reduced by massage therapy, yoga and tai chi: A review. Complementary therapies in clinical practice 2016; 22:87-92

9. Georgakis MK, Thomopoulos TP, Diamantaras AA, Kalogirou EI, Skalkidou A, Daskalopoulou SS, et al: Association of age at menopause and duration of reproductive period with depression after menopause: a systematic review and meta-analysis. JAMA psychiatry 2016; 73:139-149

10. Guo LL, Liu ZQ: Effect of hormone replacement therapy and antidepressant drugs on depression and clinical symptoms of patients with climacteric affective disorder. Chinese Journal of Practical Nervous Diseases 2015; 18:80-82

11. Haas P, Gonalves S, Oliveir J, Peruch MH: Padrão hormonal feminino: menopausa e terapia de reposição Female hormone pattern: menopause and replacement therapy. Brazilian Journal of Epilepsy \& Clinical Neurophysiology 2016; 48:198-210
12. Hildreth KL, Ozemek C, Kohrt WM, Blatchford PJ, Moreau KL: Vascular dysfunction across the stages of the menopause transition is associated with menopausal symptoms and quality of life. Menopause (New York, NY) 2018; 25:1011-1019

13. Hofmann SG, Andreoli G, Carpenter JK, Curtiss J: Effect of Hatha yoga on anxiety: a meta-analysis. Journal of Evidence-Based Medicine 2016; 9:116-124

14. Koch AK, Rabsilber S, Lauche R, Kümmel S, Dobos $G$, Langhorst J, et al: The effects of yoga and self-esteem on menopausal symptoms and quality of life in breast cancer survivors - A secondary analysis of a randomized controlled trial. Maturitas 2017; 105:95-99

15. Kroenke $K$, Baye F, Lourens $S G$ : Comparative validity and responsiveness of PHQ-ADS and other composite anxiety-depression measures. Journal of affective disorders 2019; 246:437-443

16. Lampio L, Polo-Kantola P, Himanen SL, Kurki S, Huupponen E, Engblom J, et al: Sleep during menopausal transition: a 6-year follow-up. Sleep 2017; 40:zsx090

17. Lee SB, Park SY, Jeon GS, Hong IK: Phytoestrogen Extraction for Relaxation of Female Menopause Symptoms from Natural Products. Journal of the Korean Industrial \& Engineering Chemistry 2016; 27:217-220

18. Levine ME, Lu AT, Chen BH, Hernandez DG, Singleton $A B$, Ferrucci L, et al: Menopause accelerates biological aging. Proceedings of the National Academy of Sciences 2016; 113:9327-9332

19. Li ML \& Lu LY: The Influence of Mobile Phone Addiction on Left-behind Middle School Students' Sleep Quality: the Mediator Role of Loneliness. Revista Argentina de Clinica Psicologica 2017; 26:71-81

20. Li YJ, Zou ZH, Yi SY, Yu CY: Effects of Community Management Combined with Self-management on Treatment Compliance and Quality of Life in Elderly Patients with Type 2 Diabetes. Chinese General Practice 2018; 21:71-76

21. Liang BY, Cai Y, Zhou YJ, Chen P: Development of Stress Distress Scale. Chinese Journal of Clinical Psychology 2010; 18:1-4

22. Lin HL \& Pan PS: Clinical effect of hormone replacement combined with antidepressants in the treatment of menopausal symptoms in women. Journal of Practical Gynecologic Endocrinology 2018; 5:29-31

23. Liu $Y \& X u$ RM: Effect of Yoga combined with mood training on anxiety and sleep quality of menopausal women. Chinese Journal of Physical Medicine and Rehabilitation 2019; 41:698-699

24. Loganathan N, Aruchunan M, Manjunath NK: Effects of yoga for cardiovascular and respiratory functions: a pilot study. Integrative medicine research 2019; 8:180

25. Mastura J, Omar Fauzee MS, Bahaman AS, Rashid Abd S, Somchit MN: Effect Of Low-Impact Aerobic Dance Exercise On Psychological Health (Stress) Among Sedentary Women In Malaysia. Biology of Sport 2012; 29:63-69

26. Mulhall S, Andel R, Anstey KJ: Variation in symptoms of depression and anxiety in midlife women by menopausal status. Maturitas 2018; 108:7-12

27. Pizzi S, Caputo F, Venturelli A: Accounting to ensure healthy lives: critical perspective from the Italian $\mathrm{Na}$ tional Healthcare System. Corporate Governance 2020; 20:445-460

28. Rao RM, Vadiraja HS, Nagaratna R, Gopinath KS, Patil $S$, Diwakar RB, et al: Effect of yoga on sleep quality and 
neuroendocrine immune response in metastatic breast cancer patients. Indian journal of palliative care 2017; $23: 253$

29. Ren YJ, Li ML: Influence of physical exercise on social anxiety of left-behind children in rural areas in China: The mediator and moderator role of perceived social support. Journal of Affective Disorders 2020; 266:223229

30. Rodriguez R, Svensson G, Hogevold NM, Eriksson D: Factors and determinants of value- and business-driven sustainability initiatives in health care organizations: intrinsic differences and extrinsic similarities. Corporate Governance 2019; 19:806-823

31. Sha K, Palmer MH, Yeo S: Yoga's Biophysiological Effects on Lower Urinary Tract Symptoms: A Scoping Review. The Journal of Alternative and Complementary Medicine 2019; 25:279-287

32. Ströhle A: Sports psychiatry: mental health and mental disorders in athletes and exercise treatment of mental disorders. European Archives of Psychiatry \& Clinical Neuroscience 2018; 269:1-14

33. Vodermaier A, Linden W: Social support buffers against anxiety and depressive symptoms in patients with cancer only if support is wanted: a large sample replication. Supportive Care in Cancer 2019; 27:2345-2347

34. Wang BM, Yang J, Fan MX, Liu ZY, Yu QR: FMRI Study of Yoga Exercises for Relieving Disgust Emotion:From the
Perspective of Subcortical Nerve Activity. Journal of Shenyang Sport University 2019; 38:94-99

35. Yang J, Tang S, Zhou W: Effect of Mindfulness-Based Stress Reduction Therapy on Work Stress and Mental Health of Psychiatric Nurses. Psychiatr Danub 2018; 30:189-196

36. Ye J, Zhang XL, Hu FS, Zhang YL, Sun YN, Zhang PY, et al: Exercise intensity monitoring for individualized health management. Chinese Journal of Health Management 2017; 11:265-268

37. Zeng LN, Yang Y, Feng Y, Cui X, Wang R, Hall BJ, et al: The prevalence of depression in menopausal women in China: a meta-analysis of observational studies. Journal of affective disorders 2019; 256:337-343

38. Zhang YF, Gong YJ, Tang DH, Guan Y: Effects of Acute Aerobic Exercise on Emotion Regulation Ability in Female College Students with Anxiety: Potential Mechanism and Influencing Factors. Journal of Tianjin University of Sport 2018; 33:31-37

39. Zhao D, Guallar E, Ouyang P, Subramanya V, Vaidya D, Ndumele CE, et al: Endogenous sex hormones and incident cardiovascular disease in post-menopausal women. Journal of the American College of Cardiology 2018; 71:2555-2566

40. Zung $W W$ : A self-rating depression scale. Archives of General Psychiatry 1965; 12:63-70

41. Zung WW: A rating instrument for anxiety disorders. Psychosomatics 1971; 12:371-379

Correspondence:

Xi Lu, MD

Department of Public Physical and Art Education, Zhejiang University

Hanzhou 310000, China

E-mail: 157552312@qq.com 